\title{
Distribution and Sexual Dimorphism of Palm Print Variable (Palmer Triridii Angles) Among Hausas of Kano and Zaria Metropolis, Nigeria
}

\author{
Usman Affan', L. H. Adamu² \\ ${ }^{1}$ Department of Human Anatomy, \\ College of Medical Sciences, \\ Umaru Musa Yar'adua University, \\ Katsina, Nigeria. \\ ${ }^{2}$ Department of Human Anatomy \\ College of Health Science \\ Federal University Dutse, Nigeria. \\ Email: usman.affan@umyu.edu.ng
}

\begin{abstract}
Dermatoglypics is the study of dermal ridges on finger balls, palm of the hand and sole of the feet, and provides a myriad of genetic information which are pointer to inherited genetic diseases. The aim of the study was to analyze palm prints (palmer triridii angles) among Hausas of Kano and Zaria. A total of 600 subjects comprising of 300 participants from two original Hausa metropolis (Kano and Zaria) with 1:1 male to female ratio participated. Ink method was used to capture palm prints. Chisquare was used to determine the association between the variables. The result of the study showed that a significant gender differences in the mean value were observed in the atd and dat angles in both cities and Hausas of Kano ( $t=-2.97, p<0.05$ for atd, $t=2.59, P<0.05$ for dat) with no significance in the Hausas of Zaria in right hand. However, a statistical significant difference was present in the atd and adt angles in both cities and Hausas of Kano $(t=-4.99, p<0.001$ for atd, $t=$ 5.09, $p<0.001$ for adt). For the Hausas of Zaria only the atd ( $t=-3.30, p<0.05$ for atd) angle shows significant difference. For comparison based on sex, no significant differences was observed between males from Kano and Zaria, and females from Kano and Zaria with respects to dat and adt angles of right palmer triradii. However, a significant difference was observed between Kano and Zaria males with respects to dat and adt angles of palmer triradii respectively.
\end{abstract}

Keywords: Palm prints, Palm triridii angle, Hausas, Kano, Zaria

\section{INTRODUCTION}

Dermatoglyphics is the study of dermal ridges on the balls of finger, palm of hand and sole of the feet, and provides a myriad of genetic information which are pointer to inherited genetic diseases (Reddy and Reddy, 2006; Muralidhar et al., 2011). Studies show that dermatoglyphics is used in establishing ethnic differences, genetic inheritance and population studies respectively (Harich et al., 2002; Karmakar et al., 2006; Danborno and Garba, 2007). 
The outer layer of the skin spade acquire furrow on palm layer, in association to the lower part of the $2^{\text {nd }}, 3^{\text {rd }}, 4^{\text {th }}$ and $5^{\text {th }}$ fingers equivalent to $a, b, c$ and $d$ triradius are situated respectively. The triradii ' $t$ ' also called axial triradii commonly establish in the $4^{\text {th }}$ digit axis. In 1961 Cummins and Midlo declared that triradii ' $t$ ' position normally close to a location where an individual palm is link to his wrist, that is at a distance between thenar and hypothenar eminences (Folge Thomas, 1990). Angle atd is formed simply by lines draw from ' $a$ ' triradius to axial and from $d$ ' triradius to axial or triradius $t^{\prime}$. For individuals under normal health conditions the angel atd usually fall within an average of $48^{\circ}$. This angle is deliberate in an adducted palm, which yield more measurement by $10^{\circ}$. Determination of angle atd of the palm was instructed in 1954 by Panrose (Mellor C.S., 1968).

In a study conducted in India an attempt was made at finding the relationship between dermatoglypics form of healthy individuals and the patients Diagnosed with Diabetes Mellitus. The result shows that the mean atd angle on the right hand were $39.43^{\circ}$ and $41.13^{\circ}$ in the healthy and diabetic groups respectively, while on left hand it was $39.3^{\circ}$ and $41.47^{\circ}$ respectively. On the other hand, angle tda on the right hand of the control and diabetic groups was found to be $81.18^{\circ}$ and $80.35^{\circ}$ respectively, while on left hand it was $81.26^{\circ}$ and $80.17^{\circ}$ respectively. A statistical significant difference was noticed in atd and tda angle of control and diabetic group. On the right hand of both the control and diabetic group the dat angle were $59.39^{\circ}$ and $58.52^{\circ}$ respectively, while on left hand, it was $59.44^{\circ}$ and $58.36^{\circ}$ respectively. Statistical significant difference was not observed in dat angle of control and diabetic group (Mittal and Lala, 2013).

Previous studies reported that the mean atd angles were $43.49^{\circ}$ for males and $44.02^{\circ}$ for females; tad angles were $75.11^{\circ}$ for males and $74.71^{\circ}$ for females; and tda were $61.22^{\circ}$ for males and $61.35^{\circ}$ females (Adetona et al., 2012). The atd angle might be additionally pointed to for problematic usage on the grounds of printing difficulties; the atd angle can change depending on pressure applied and whether fingers are closely approximated or splayed (Mavalwala et al., 1981). The atd angle is also notable for being sex and age related: the angle tends to be broader in males, and it decreases with age as the palm grows more in length than in breadth (Schaumann and Alter, 1976).

The Hausa ethnic group is one of Nigeria's largest ethnic groups, but data on their human biology is scarce. The present study intends to describe the nature of palm print variable (palmer triridii angles; atd, adt and dat) of Hausas from Kano and Zaria, Nigeria.

There is paucity of anthropological data on the ethnic groups in Nigeria especially the Hausa ethnic group. This served as the impetus for the present study. Thus, Result from the present study will add on the few available data on the human biology of the Hausa ethnic group. It will also contribute to the providing the overall picture of the biological traits of the Nigerian population.

\section{MATERIALS AND METHOD}

\section{Study Location and Population}

The study was conducted in the two Hausa cities which comprises of Kano and Zaria metropolis, which is the north-west of Nigeria. Data for this study was collected from participants after informed verbal consent was obtained from those who were willing to participate in the survey, using a stamp pad, printer's duplicating ink, microscopic slide, methylated spirit, cotton wool and white plain sheets of paper. A total of six hundred (600) participants were selected using systematic random sampling method with a sex ratio of 1:1. 


\section{Palm print collection}

In this research work an offline method of palm print acquisition was employed, in which the palm print data was collected or captured from a non-digital source. Instead, the participants palm print was collected by printing with an ink on to a white paper sheet (Champed et al., 2004). Palm prints were taken with the subjects sitting in a relaxed position with hands washed and dried. Little amount of stamp pad ink was applied over the palm of the subject by simply pressing their palm on the provided stamp pad, making sure that each and every participant palm cupped region was thoroughly and uniformly. The questionnaire was placed on the table where the palm was imprinted, making sure that the cupped regions of the palm are printed properly by pressing the dorsum of the palm of the subject. Care was taken to avoid wrinkles and air bubbles. Then the palm prints was study carefully using magnifying glass in bright light and the values of palm triridii angles were obtained from the palm print.

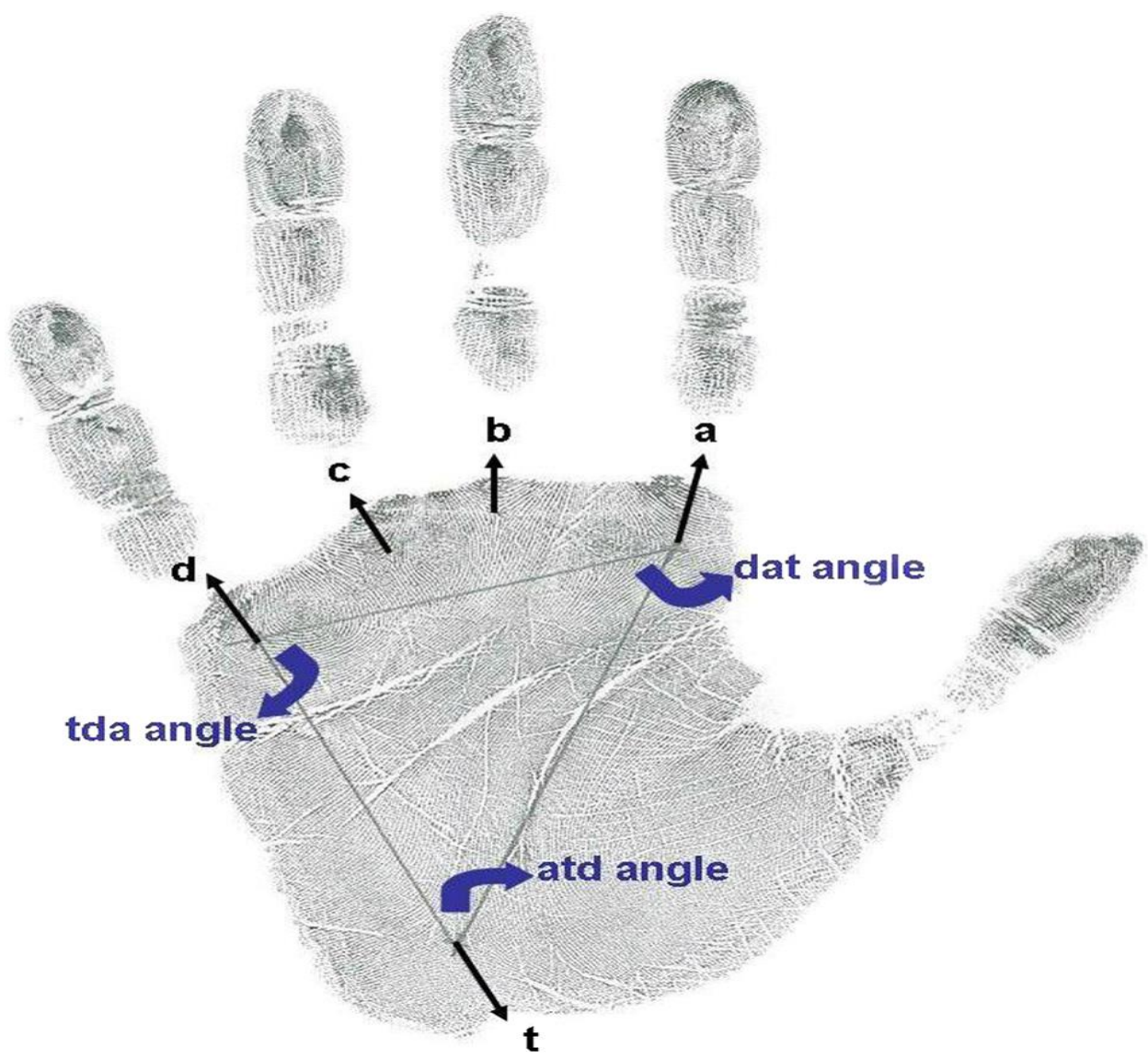

Fig. 3.1, Palm print showing locations of triradii and the palm angles (Bukelo et al., 2011).

\section{Ethical Clearance}

Ethical clearance was obtained from research ethics committee Ahmadu Bello University Teaching Hospital, Zaria. Nigeria.

\section{Statistical Analyses}

SPSS version 22 (IBM, Corp., New York) was used for the data analysis. Data was reported using descriptive statistics of frequency/percentages. Chi-square test was used to test for association between qualitative variables and $p<0.05$ was deemed statistically significant. 


\section{RESULT}

Significant gender differences in the mean value was observed in the atd and dat angles in both study area $(\mathrm{t}=-2.97, \mathrm{P}<0.05$ for atd, $\mathrm{t}=2.59, \mathrm{P}<0.05$ for dat $)$ though no significant difference was observed in the right hand of the Zaria subjects. However, a statistical significant difference was observed in the atd and adt angles of both study areas (i.e. $t=-4.99$, $\mathrm{P}<0.001$ for atd, $\mathrm{t}=5.09, \mathrm{P}<0.001 \mathrm{for}$ adt) (Figure 4.3). For the Hausas of Zaria, only the atd $(\mathrm{t}=-3.30, \mathrm{P}<0.05$ for atd) angle showed significance (Figure 4.4). With respect to sex, no significant differences was observed between males from Kano and Zaria as well as females from Kano Zaria i.e. with respect to the angles of right palmer triradii (Figure 4.5). However, a significant differences was observed between males from Kano and Zaria with respect to the dat and adt angles of left palmer triradii (Figure 4.5).

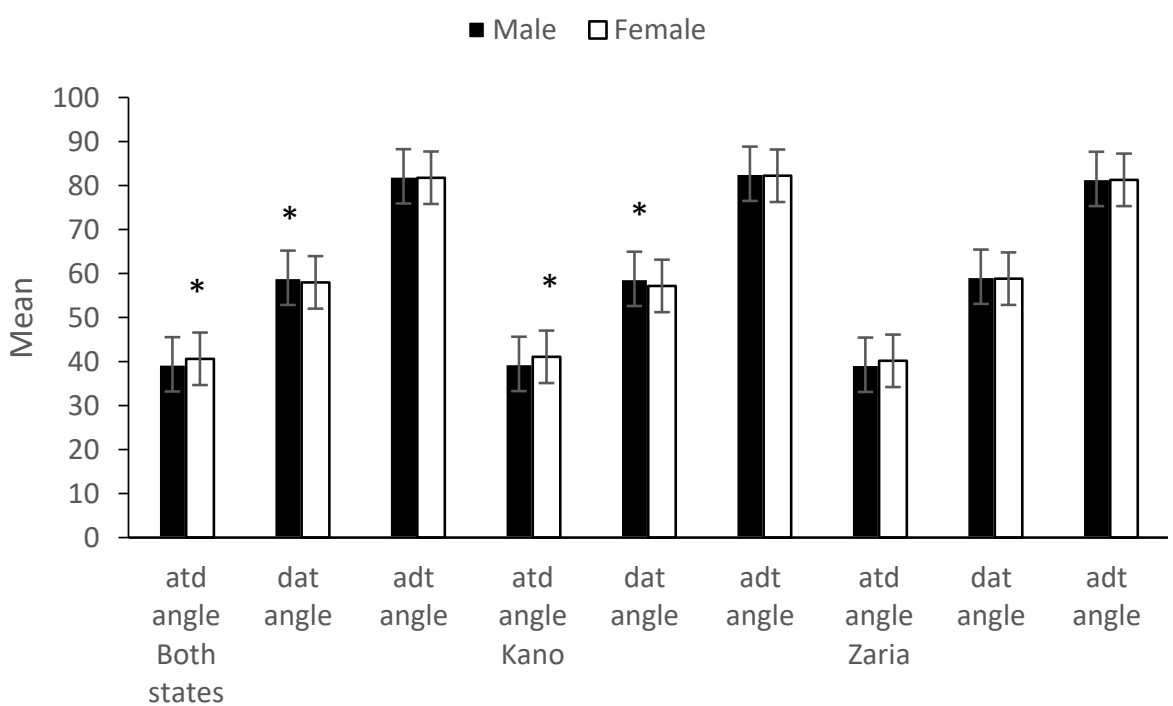

Fig. 4.3: Sexual dimorphism in mean value of right palmer triridii angles from Hausas of Kano and Zaria * $\mathrm{p}<$ 0.05

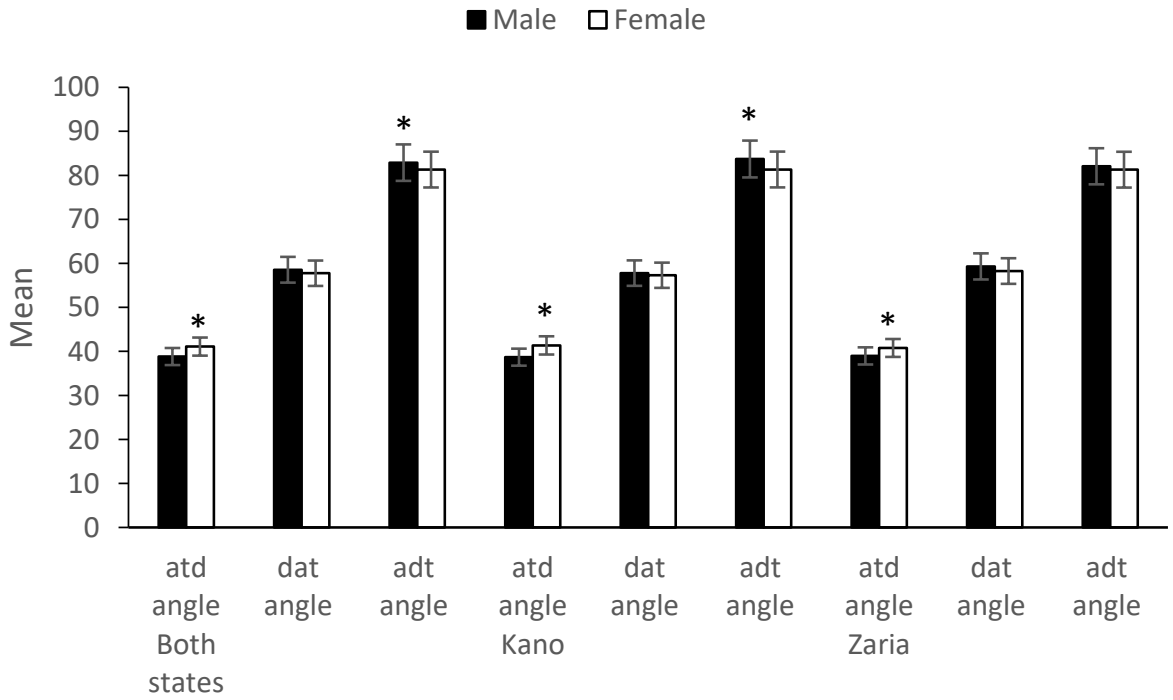

Fig. 4.4: Sexual dimorphism in mean value of left palmer triridii angles from Hausas of Kano and Zaria * $\mathrm{p}<0.05$. 


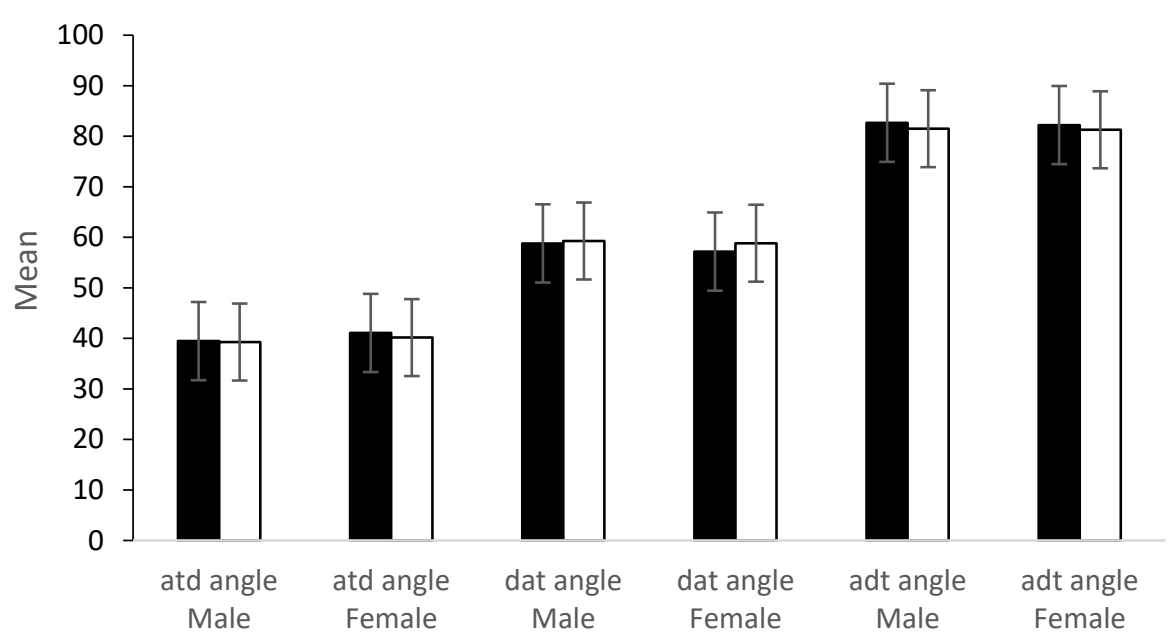

Fig. 4.5: Differences in mean value of right palmer triridii angles of males and females of Kano and Zaria

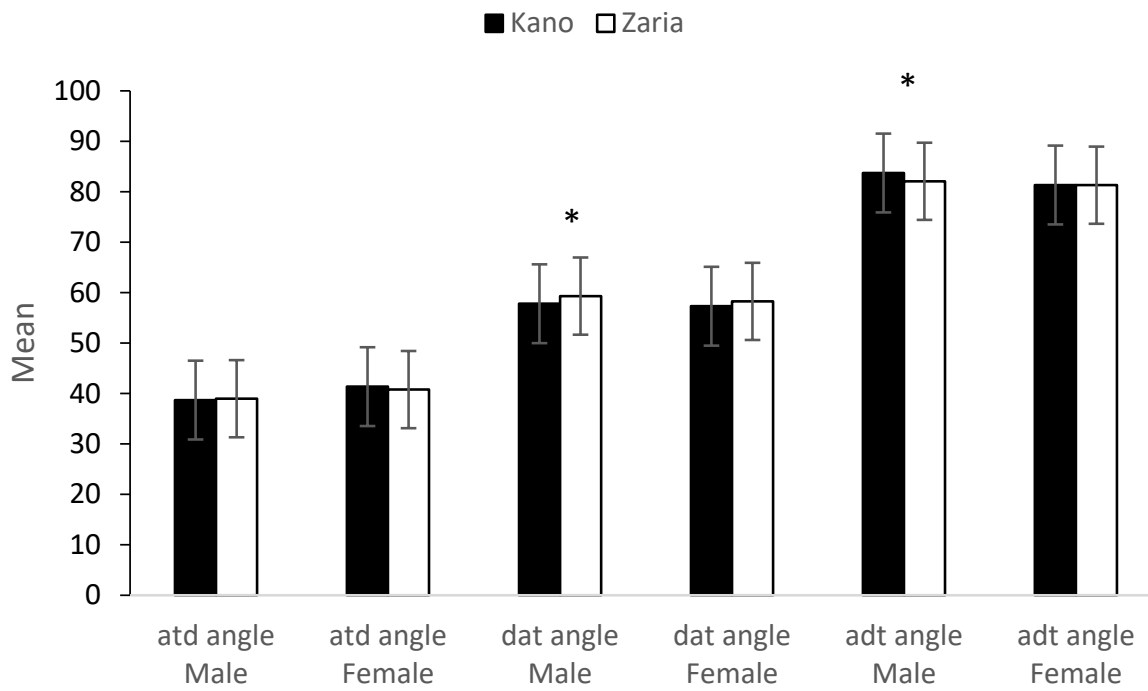

Fig. 4.6: Differences in mean value of left palmer triridii angles of males and females of Kano and Zaria * $p<$ 0.05

\section{DISCUSSION}

The present study showed a significant gender difference in the mean value of the atd and dat angles in both states. Similarly, the differences was noticed only in the Hausas of Kano with no significance in the Hausas of Zaria in right hand. For the left hand, a statistical significant differences were present in the atd and adt angles in the combine Hausas population and Hausas of Kano when separated. For the Hausas of Zaria only the atd angle shows significant differences. The male tend to have lower mean value in both right $\left(39.46^{\circ}\right.$ vs $\left.41.07^{\circ}\right)$ and left $\left(38.69^{\circ}\right.$ vs $\left.41.36^{\circ}\right)$ in Hausas of Kano and that of Zaria (right hand $=39.27^{\circ}$ vs $41.16^{\circ}$, left hand $=38.97^{\circ}$ vs $40.78^{\circ}$ ) in atd angles only. However, in the dat and adt angles the female tends to have higher mean values compared with their male counterparts.

This is similar to the findings of Adetona et al., 2012 who reported mean atd angles of 43.49 for males and 44.02 for females; tad angles of 75.11 for males and 74.71 for females; and tda of 61.22 for males and 61.35 for males and females respectively. When comparing the two population, it was noticed that the Hausas have lower mean values in atd and tad/dat with 
higher mean values in adt/tda. This may reveal the potential of these angles in ethnic discrimination as well as in intraethnic differentiation especially in an ethnic group were heterogeneity occur as seen in Hausa where they are classified in seven original Hausas state; including Zaria and Kano. On the contrary the present finding disagrees with other findings that documented that angle atd is renowned for being sex and age connected with males showing wider angle, this shows decrease as the age increases this is because palm grows more in length than in breadth (Schaumann and Alter, 1976).

It is also state that the atd angle might be additionally pointed to for problematic usage on the grounds of printing difficulties as; the atd angle can change depending on pressure applied and whether fingers are closely approximated or splayed (Mavalwala et al., 1981).

Base on sex, no significant differences was observed between males from Kano and Zaria, and females from Kano and Zaria with respect to the angles of right palmer triradii. However, a significant differences was observed between males from Kano and Zaria with respect to dat and adt angles of palmer triradii. This finding reveled that though the population was compose of Hausas ethnic group variations were observed with respect to the angles of palmer triradii. This variation may be due to the differences in their genetic make-up.

\section{CONCLUSION}

The finding of the present study suggests that palmer triridii angles can give more insight into the differences that may exist between the two Hausa groups with the males having lower mean value in both right $\left(39.46^{\circ}\right.$ vs $\left.41.07^{\circ}\right)$ and left $\left(38.69^{\circ}\right.$ vs $\left.41.36^{\circ}\right)$ palms of the subjects from Kano and Zaria (right hand $=39.27^{\circ}$ vs $41.16^{\circ}$, left hand $=38.97^{\circ}$ vs $40.78^{\circ}$ ) with respects to atd angles only. However, in the dat and adt angles the females had higher mean values as compared to their male counterparts.

\section{AKNOWLEDGEMENT}

We will like to acknowledge the contribution of Professor S. B. Danborno and Dr. W. O. Hamman from Ahmadu Bello University Zaria for their guidance and constructive criticism in designing and carrying out the study. We also thank to participants of this study for giving their consent in this study.

\section{REFERENCES}

Adetona, M. O., Oladapo, O. O. and Akinyemi, J. O. (2012). Palmar flexion creases variants among Nigerians. African Journal of Biomedical Research, 15, 93-96.

Bukelo, M. J., Kanchan, T., Rau, A. T. K., Unnikrishnan, B., Bukelo, M. F. and Krishna, V. N. (2011). Palmar dermatoglyphics in children with acute lymphoblastic leukemia. A preliminary investigation. Journal of Forensic and Legal Medicine, 18, 115-118

Champed, C., Lennard, C., Margot, P. and Stoilovic, M. (2004). Fingerprints and other Ridge Skin Impressions. Boca Raton, Florida: CRC Press.

Danborno, B. and Idris, G. (2007). Digital dermatoglyphics of Hausa ethnic group of Nigeria. Journal of Experimental and Clinical Anatomy. 6: 36-40.

Fogle Thomas, (1990). Using Dermatoglyphics from Down Syndrome and Class Populations to Study the Genetics of a Complex Trait. [Online] Association for Biology Laboratory Education (ABLE). Available at: http://www.zoo.utoronto.ca/able [accessed 17 December, 2012] 
Harrich, N., Esteban, E., Chafik, A. and Moral, P. (2002). Dermatologic characterization of barbars from Morocco. Qualitative and quantitative digital and palmer data. American Human Biology, 29: 442 -456.

Karmakar, B., Yakovenko, K. and Kobyliansky, E. (2006). Mode of inheritance of dermatoglyphics pattern intensity index on finger in five Indian population: A comparative study between individual traid and its factor. American journal of human biology, 18: 377-386.

Mavalwala, J. (1981). The atd angle: a critique. Birth defects Original Article Series 15: 169-72.

Mellor C.S., 1968. Dermatoglyphic in Schizophrenia: Part I: Qualitative Aspects. BJ Psych the British Journal of Psychiatry [on line] Available at http: //bjp.rcpsych.org/ site/ subscriptions/ [accessed 15 December, 2012]

Mellor C.S., (1968). Dermatoglyphic in Schizophrenia: Part II: Quantitative study. BJ Psych the British Journal of Psychiatry [on line] Available at http: //bjp.rcpsych. org/site/subscriptions/ [accessed 15 December, 2012]

Mittal Mukesh and Lala B. S. (2013). Dermatoglyphics: An economical tool for prediction of diabetes mellitus. International Journal of Medical and Health Sciences, 2 (3), 293-294.

Muralidhar, R. S., Ramesh, B. A. and Krupadanam, K. (2011). Finger Print Pattern in Different Blood Group, Journal of Indian Academic Medicine, 33: 4.

Reddy, B.K.C. and Reddy, K.S.N. (2006). A study of salmar dermatoglyphics among Sugalis, a tribal population of Andhra pradesh. Anthropologist, 8: 21-24.

Schaumann, B. and Alter, M. (1976). Dermatoglyphics in medical disorders. New York: Springer Verlag, 187-189. 